\title{
Bei Periimplantitis
}

Mit dem Set 4656 hat der Zahnarzt alle Instrumente für eine chirurgisch/resektive Periimplantitisbehandlung, also Glättung des Implantatgewindes, zur Hand. Gemeinsam mit Dr. Martin Dürholt, Bad Salzuflen, entwickelte Komet 8 Hartmetallinstrumente in Ei- und Flammenform

(H379/

H379UF

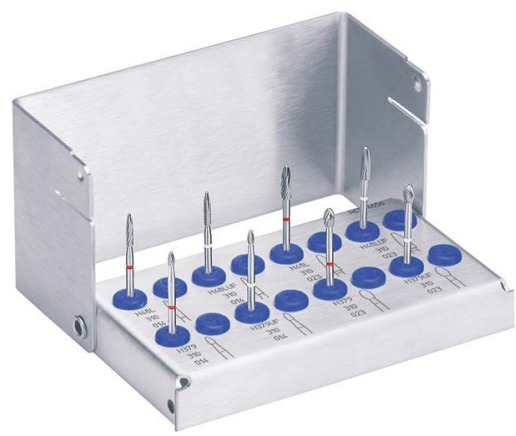

und

H48L/

H47LUF)

für die in-

traorale

Titanbe-

arbei-

tung. Je-

des Inst-

rument

steht in 2
Größen (1,4 und 2,3 mm) als Rotring mit normaler Verzahnung und formkongruent als Weißring mit ultrafeiner Verzahnung zur Verfügung. Je nach Form und Länge ermöglichen die Spezialinstrumente (30 mm Gesamtlänge) die Glättung des Implantatgewindes selbst in schwierig zugänglichen, tiefen Arealen. Sie werden im roten Winkelstück ,gegen den Uhrzeigersinn" um das Implantat herum sicher geführt. Das Ergebnis ist eine glatte, saubere Titanoberfläche, die der Plaque zukünftig wenig Retentionschance gibt. Damit bietet das Set 4656 die beste Prognose für eine sichere Fortbehandlung.

Nach einer Pressemitteilung der

Komet Dental Gebr. Brasseler GmbH \& Co KG,

Lemgo

www.kometdental.de 